\title{
EFEITO DO ESPAÇAMENTO E DO NÚMERO DE MUDAS POR COVA NA PRODUÇÃO DE RÚCULA NAS ESTAÇÕES DE OUTONO E INVERNO
}

\author{
Effect of within row spacing and number of seedlings \\ per hole on autumn and winter season
}

\author{
Marie Yamamoto Reghin ${ }^{1}$, Rosana Fernandes Otto ${ }^{1}$, Jean Ricardo Olinik², Carlos Felipe Stülp Jacoby ${ }^{2}$
}

\begin{abstract}
RESUMO
A rúcula (Eruca sativa Hill.) é uma hortaliça folhosa que tem apresentado nos últimos anos aumento crescente de produção no Brasil. Por outro lado, poucas pesquisas são realizadas na cultura, sendo escassas as recomendações de cultivo e manejo, que otimizem sua produção. Neste contexto, o presente trabalho teve como objetivo avaliar respostas produtivas da rúcula em função do espaçamento entre plantas, com densidade de duas ou quatro mudas por cova, durante as estações de outono e de inverno, em Ponta Grossa (PR). O delineamento experimental utilizado foi o de blocos casualizados, com quatro repetições. Os tratamentos foram arranjados conforme fatorial 4 x 2, sendo quatro espaçamentos entre plantas $(5,10,15$ e $20 \mathrm{~cm})$ e duas densidades de mudas por célula $(2$ e 4$)$. As mudas foram produzidas em bandejas de poliestireno expandido de 200 células sob ambiente protegido, usando a cultivar Cultivada, durante o período de 28/03/2003 a 16/04/2003, na estação de outono e no período de 11/07/2003 a 05/08/2003, na estação de inverno respectivamente. A semeadura constou de duas ou quatro sementes por célula. Cada parcela constou de 32 plantas, dispostas em quatro fileiras espaçadas de $20 \mathrm{~cm}$ entre si. Na colheita, aos trinta dias do transplante para a estação de outono e de trinta e cinco dias na estação de inverno, foram avaliadas: comprimento da parte aérea, número de folhas, massa fresca e seca por planta e rendimento de massa fresca. $\mathrm{m}^{-2}$. Ao considerar a característica individual da planta, ocorreu resposta produtiva superior na densidade de duas mudas e espaçamentos mais amplos, de 15 e $20 \mathrm{~cm}$, quanto ao comprimento da parte aérea, número de folhas e massa fresca e seca por planta. No entanto, considerando que a comercialização predominante da rúcula é em maços, o menor espaçamento na estação de outono e tanto o menor espaçamento quanto a maior densidade na estação de inverno, foram os fatores que promoveram maior rendimento em massa fresca.m-2. Comparada à estação de inverno, houve precocidade de colheita de 11 dias no outono quando predominaram temperaturas médias em torno de $20^{\circ} \mathrm{C}$.
\end{abstract}

Termos para indexação: Eruca sativa, densidade de mudas, espaçamento entre plantas.

\begin{abstract}
Rocket crop has presented increment of production in Brazil. In the other hand it has been noted the research in this crop is rare and insufficient to give enough support to increase yield. On the strength of it the present experiment had the aim to avaluate yield response on rocket crop in function of within row spacing with density of two or four seedlings per hole, during autumn and winter season in Ponta Grossa (PR). The experimental design was a randomized blocks with four replications. The treatments were arranged in a factorial scheme $4 \times 2$, being four within row spacing $(5,10,15$ and $20 \mathrm{~cm}$ ) and two density of seedlings per cell (two or four). The seedlings were produced on trays of 200 cells under protected cultivation, with the cultivar Cultivada, during the period of March, 28 to April, 16 on Autumn season, and at July, 11 to August, 5 on winter season. Four or two seeds per cell were sowed. Each plot had 32 plants, arranged in four rows spaced $20 \mathrm{~cm}$ among them. At harvest at thirty days of transplanting on autumn season and at thirtyfive days on winter season it was avaluated: lenght of upper part, leaves number, fresh and dried matter and yield of fresh matter.m ${ }^{-2}$. On the individual plant characteristic it was observed superior yield response of two seedlings/cell density and within row as 15 and 20 $\mathrm{cm}$ on lenght of upper part, leaves number, fresh and dried matter weight per plant. However, considering the usual way of commercialization of rocket mainly on bunch the narrow within row spacing as $5 \mathrm{~cm}$ on autumn season and both the narrow within row spacing and density of four seedlings promoted the highest yield on fresh matter weight. $\mathrm{m}^{-2}$. Compared to winter season it was observed earlier harvest about 11 days in autumn when predominated temperatures around $20^{\circ} \mathrm{C}$.
\end{abstract}

Index terms: Eruca sativa, seedlings density, within row spacing.

(Recebido para publicação em 02 de junho de 2004 e aprovado em 10 de março de 2005)

\section{INTRODUÇÃO}

A rúcula (Eruca sativa Hill.) é uma hortaliça herbácea anual, de porte baixo, possuindo normalmente altura de $15 \mathrm{a} 20 \mathrm{~cm}$, com folhas verdes e recortadas, tendo como centro de origem e de domesticação do gênero Eruca, o Mediterrâneo e o oeste da Ásia.
O seu cultivo comercial tem aumentado nos últimos anos em muitos países da Europa, sendo consumida principalmente como salada. Além do seu uso na alimentação, também é considerada planta medicinal com muitas propriedades, tais como: digestiva, diurética, estimulante, laxativa e antiinflamatória, além de ser fonte de vitamina $\mathrm{C}$ e ferro. No Paquistão, tipos especiais de $E$.

\footnotetext{
1 Doutoras, Professoras Adjunto de Olericultura do Departamento de Fitotecnia e Fitossanidade - Universidade Estadual de Ponta Grossa/PR Campus de Uvaranas - freghin@convoy.com.br

${ }^{2}$ Bolsistas de IC (CNPq), acadêmicos do $3^{0}$ ano do curso de Agronomia da Universidade Estadual de Ponta Grossa/PR - Campus de Uvaranas.
} 
sativa são cultivadas para produção de sementes, que são usadas para extração de óleo, rico em ácido erúcico, componente importante na indústria (PADULOSI \& PIGNONE, 1996).

No Brasil, trata-se de uma folhosa com crescente incremento de consumo nos últimos anos, com quantidade mensal de 16.029 dúzias de maços de $6 \mathrm{~kg}$ comercializados no CEAGESP, entre 1995 a 1999 (CAMARGO FILHO \& MAZZEI, 2001).

Para o seu cultivo, Minami \& Tessarioli Neto (1998) recomendam um preparo bem feito do canteiro, com semeadura na quantidade de 0,2 a 0,3 g por metro linear e após a emergência, realizar o desbaste do excesso de plantas, se necessário.

Filgueira (2000) relata que a semente é semeada diretamente em canteiro definitivo, em sulcos longitudinais distanciados $20-30 \mathrm{~cm}$, deixando-se as plantas espaçadas de $5 \mathrm{~cm}$, após o desbaste.

$\mathrm{Na}$ semeadura direta vários fatores estão envolvidos, e muitas vezes é difícil obter um estande uniforme porque as sementes ficam submetidas à condições desuniformes de solo, ocorrência de chuvas ou temperaturas extremas, principalmente se tratando de sementes pequenas como as da rúcula que possui em um grama, cerca de 650 sementes.

Para o produtor que objetiva colheita de safras durante o ano todo é necessário otimização da produção e obtenção de alto rendimento do produto, que apresente uniformidade e alta qualidade. Neste tipo de cultivo, é altamente prejudicial contar com falhas ou desuniformidade no estande. O cultivo com mudas transplantadas é uma das alternativas para contornar essa ocorrência.

Outro fator que determina o rendimento e a qualidade do produto é o espaçamento usado na cultura. Takaoka \& Minami (1984) observaram que os espaçamentos entre linhas mais vantajosos para a rúcula foram os de 15, 20 e $25 \mathrm{~cm}$, todos com a mesma densidade de semeadura. Não foram encontradas recomendações de espaçamentos entre plantas.

O presente trabalho teve como objetivo avaliar o efeito de diferentes espaçamentos entre plantas no cultivo de rúcula, com mudas provenientes de bandejas com densidade de duas ou quatro mudas por cova, durante a estações de outono e de inverno.

\section{MATERIAL E MÉTODOS}

Os experimentos foram conduzidos na Universidade Estadual de Ponta Grossa, em Ponta Grossa (PR), localizada a $880 \mathrm{~m}$ de altitude, em solo do tipo CAMBISSOLO HÁPLICO Tb Distrófico, de textura argilosa. O delineamento experimental em cada um dos experimentos foi o de blocos casualizados, com quatro repetições; os tratamentos em ambos experimentos foram distribuídos segundo esquema fatorial 4 × 2 , constando de espaçamentos entre plantas de $5,10,15$ e $20 \mathrm{~cm}$ e densidade de 2 e 4 mudas por célula.

As mudas foram produzidas em bandejas de poliestireno expandido de 200 células, usando-se sementes da cultivar Cultivada (Agroflora) e o substrato Plantmax, sob cultivo protegido em estrutura metálica de arcos, coberta com polietileno transparente de 120 micras, durante o período de 28/03/2003 a 16/04/2003, na estação de outono e de 11/07/2003 a 05/08/2003, na estação de inverno, respectivamente. A semeadura constou de duas ou quatro sementes por célula.

O transplante foi realizado em 16/04 no outono e em 05/08 no inverno, em solo preparado previamente, cuja adubação básica foi realizada com a fórmula 5-25-10, na quantidade de $100 \mathrm{~g} \cdot \mathrm{m}^{-2}$. As parcelas foram perfuradas com marcadores nos espaçamentos testados, e cada uma constou de quatro fileiras de plantas no espaçamento de $20 \mathrm{~cm}$ entre linhas, totalizando 32 plantas por parcela. A área foi mantida com irrigação por gotejamento.

Durante o desenvolvimento vegetativo, aos quinze dias do transplante, fez-se adubação nitrogenada em cobertura com uréia na quantidade de $10 \mathrm{~g}$ por metro linear. Na colheita, aos trinta dias do transplante para a estação de outono e de trinta e cinco dias na estação de inverno, foram avaliadas: comprimento da parte aérea, número de folhas por planta, massa fresca e seca por planta e rendimento de massa fresca. $\mathrm{m}^{-2}$. Tanto na densidade de duas ou de quatro mudas, realizou-se a avaliação individual de cada planta e usou-se o valor médio para a respectiva característica avaliada. A massa seca da parte aérea foi obtida em estufa de ventilação forçada a $60^{\circ} \mathrm{C}$, até atingir massa constante. Os dados foram submetidos à análise de variância e as médias comparadas pelo teste de Tukey no nível de 5\% de probabilidade.

\section{RESULTADOS E DISCUSSÃO}

\section{Estação de outono}

Os valores das médias para as características avaliadas encontram-se nas Tabelas 1, 2 e 3. Houve interação significativa para número de folhas e massa fresca e seca da planta. Já, para as características de comprimento da parte aérea e rendimento de massa fresca por área, não houve interação significativa.

Ciênc. agrotec., Lavras, v. 29, n. 5, p. 953-959, set./out., 2005 
Não houve efeito do espaçamento no comprimento da parte aérea das plantas. No entanto, o comprimento variou em função da densidade de mudas, demonstrando que com quatro mudas, a competição exercida pelo maior número de plantas na cova, promoveu um decréscimo nesse comprimento, de $26,84 \mathrm{~cm}$ ( 2 mudas por cova) para $24,53 \mathrm{~cm}$ (4 mudas por cova), (Tabela 1).

O número de folhas variou em função do espaçamento entre plantas e da densidade de mudas. Em todos os espaçamentos, exceto no de $5 \mathrm{~cm}$, verificou-se maior número de folhas na densidade de duas mudas, quando comparada à quatro mudas. Reghin et al. (2004) observaram que a densidade de mudas por célula promoveu respostas produtivas significativas no cultivo da rúcula. A medida que ocorreu aumento da densidade (de uma para quatro mudas) houve diminuição da altura, número de folhas, massa fresca e seca por planta.

Somente na densidade de duas mudas, houve efeito significativo do espaçamento entre plantas. À medida que houve aumento do espaçamento entre plantas, ocorreu aumento do número de folhas. Com densidade de quatro mudas, o espaçamento entre plantas não exerceu influência significativa, provavelmente pela própria concorrência exercida pela densidade de plantio. Nesse caso, embora as plantas tenham um espaçamento entre plantas maior como o de $20 \mathrm{~cm}$, não houve efeito significativo, pois mais efetivo que o espaçamento foi a densidade de quatro mudas. Independentemente do plantio em espaçamento entre plantas de 5 ou de $20 \mathrm{~cm}$, o número de folhas não apresentou diferença significativa em função da pressão exercida primordialmente pela densidade de plantio (Tabela 1).

Pode-se dizer que a rúcula demonstrou bastante sensibilidade à densidade de plantio. Com duas mudas, observou-se superioridade da massa fresca como da seca (Tabela 2), comparada à quatro mudas, em consequência do maior desenvolvimento em altura e número de folhas. Nessa densidade, pela menor concorrência existente entre as plantas, estas apresentaram aumento crescente da massa de acordo com o aumento do espaçamento. Os maiores valores foram observados com 15 e $20 \mathrm{~cm}$, os quais diferiram estatisticamente dos demais, com 5 e $10 \mathrm{~cm}$. Comparando os espaçamentos de 5 e $20 \mathrm{~cm}$, a diferença encontrada foi de $18,69 \mathrm{~g}$ a favor do maior espaçamento, confirmando que este fator de produção é essencial para definir o tipo de produto que se objetiva produzir.

Com menor densidade (duas mudas), pode-se obter um produto com massa média de 31,90 e 36,36 g por planta, respectivamente, nos espaçamentos de 15 e $20 \mathrm{~cm}$. Do ponto de vista comercial essas plantas têm atributos para serem padronizados como produto de ótima qualidade pela aparência vistosa, tendo mais de $25 \mathrm{~cm}$ de porte e mais de 15 folhas.

No entanto, se trabalhar com densidade de quatro mudas, nestes mesmos espaçamentos, ter-se-á como resultado plantas de 15,62 e $18,37 \mathrm{~g}$, com média de $24,1 \mathrm{~cm}$ e 10,3 folhas, bem menores que as anteriores (Tabela 2). Deste modo, com alta densidade (quatro mudas), mesmo em espaçamentos mais amplos (15 e $20 \mathrm{~cm}$ ), não ocorreu efeito de compensação pois as plantas obtidas foram significativamente menores.

Os valores da temperatura média mostraram que na fase inicial de desenvolvimento da planta, houve predominância da temperatura média em torno de $20^{\circ} \mathrm{C}$ até a data de 04/05, quando ocorreu decréscimo da temperatura e registrou-se médias abaixo de $15^{\circ} \mathrm{C}$ até dia 12/05 (Figura 1).

TABELA 1 - Comprimento da parte aérea $(\mathrm{cm})$ e número de folhas por planta, em função do espaçamento entre plantas e densidade de duas e quatro mudas por cova no cultivo da rúcula. Ponta Grossa, PR. 2003. Estação de outono.

\begin{tabular}{cccccc}
\hline \multicolumn{2}{c}{ Comprimento da parte aérea $(\mathbf{c m})$} & \multicolumn{3}{c}{ Número de folhas por planta } \\
\hline $\begin{array}{c}\text { Esp. entre plantas } \\
(\mathrm{cm})\end{array}$ & $\begin{array}{c}\text { Duas } \\
\text { mudas/cova }\end{array}$ & $\begin{array}{c}\text { Quatro } \\
\text { mudas/cova }\end{array}$ & Média & $\begin{array}{c}\text { Duas } \\
\text { mudas/cova }\end{array}$ & $\begin{array}{c}\text { Quatro } \\
\text { mudas/cova }\end{array}$ \\
\hline 5 & 28,06 & 24,62 & $26,34 \mathrm{a}$ & $10,61 \mathrm{~A} \mathrm{c}$ & $8,85 \mathrm{~A} \mathrm{a}$ \\
10 & 26,17 & 25,26 & $25,72 \mathrm{a}$ & $12,70 \mathrm{~A} \mathrm{bc}$ & $9,36 \mathrm{~B} \mathrm{a}$ \\
15 & 27,56 & 23,72 & $25,64 \mathrm{a}$ & $15,00 \mathrm{~A}$ ab & $10,20 \mathrm{~B} \mathrm{a}$ \\
20 & 25,57 & 24,53 & $25,99 \mathrm{a}$ & $16,02 \mathrm{~A} \mathrm{a}$ & $10,45 \mathrm{~B} \mathrm{a}$ \\
\hline Média & $26,84 \mathrm{~A}$ & $24,53 \mathrm{~B}$ & & & \\
\hline
\end{tabular}

*Médias seguidas da mesma letra maiúscula na linha e minúscula na coluna, não diferem significativamente entre si no nível de $5 \%$ de probabilidade pelo teste de Tukey. 
TABELA 2 - Massa fresca e seca (g/planta) em função do espaçamento entre plantas e densidade de duas e quatro mudas por cova no cultivo da rúcula. Ponta Grossa, PR. 2003. Estação de outono.

\begin{tabular}{ccccc}
\hline & \multicolumn{2}{c}{ Massa fresca (g/planta) } & \multicolumn{2}{c}{ Massa seca (g/planta) } \\
\hline $\begin{array}{c}\text { Esp. entre plantas } \\
(\mathrm{cm})\end{array}$ & $\begin{array}{c}\text { Duas } \\
\text { Mudas/cova }\end{array}$ & $\begin{array}{c}\text { Quatro } \\
\text { Mudas/cova }\end{array}$ & $\begin{array}{c}\text { Duas } \\
\text { Mudas/cova }\end{array}$ & $\begin{array}{c}\text { Quatro } \\
\text { Mudas/cova }\end{array}$ \\
\hline 5 & $17,67 \mathrm{~A} \mathrm{~b}$ & $10,56 \mathrm{~B} \mathrm{~b}$ & $1,31 \mathrm{~A} \mathrm{~b}$ & $0,80 \mathrm{~B} \mathrm{~b}$ \\
10 & $22,80 \mathrm{~A} \mathrm{~b}$ & $13,75 \mathrm{~B} \mathrm{ab}$ & $1,78 \mathrm{~A} \mathrm{~b}$ & $0,97 \mathrm{~B} \mathrm{~b}$ \\
15 & $31,90 \mathrm{~A} \mathrm{a}$ & $15,62 \mathrm{~B} \mathrm{ab}$ & $2,47 \mathrm{~A} \mathrm{a}$ & $1,10 \mathrm{~B} \mathrm{ab}$ \\
20 & $36,36 \mathrm{~A} \mathrm{a}$ & $18,37 \mathrm{~B} \mathrm{a}$ & $2,82 \mathrm{~A} \mathrm{a}$ & $1,46 \mathrm{~B} \mathrm{a}$ \\
\hline
\end{tabular}

*Médias seguidas da mesma letra maiúscula na linha e minúscula na coluna, não diferem significativamente entre si, no nível de $5 \%$ de probabilidade, pelo teste de Tukey.

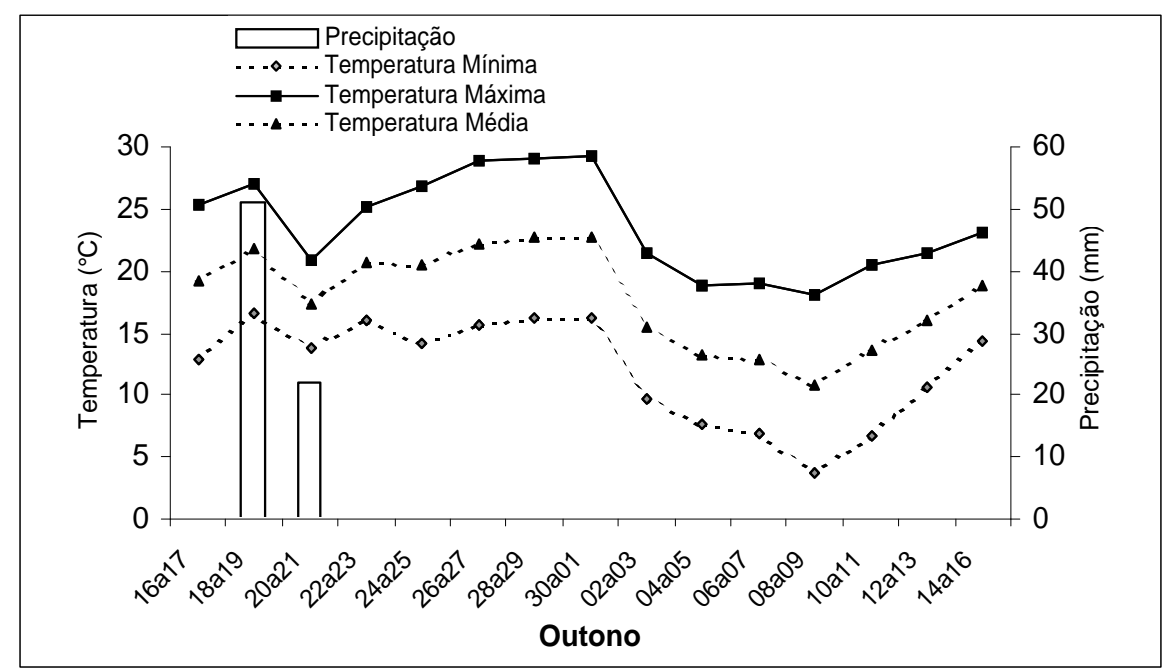

FIGURA 1 - Temperaturas máximas, médias e mínimas $\left({ }^{\circ} \mathrm{C}\right)$ a cada dois dias e soma semanal da precipitação (mm) no período Abril/2003 a Maio/2003. Ponta Grossa (PR).

*Fonte: Instituto Agronômico do Paraná.

De forma geral, as temperaturas amenas que predominaram no período favoreceram o desenvolvimento vegetativo da planta (Figura 1).

No rendimento em massa fresca por área evidenciou-se o efeito promovido pela alta população, no menor espaçamento (Tabela 3 ). Com os espaçamentos de $5,10,15$ e $20 \mathrm{~cm}$ e densidade de duas mudas, trabalhou-se respectivamente com as seguintes populações de plantas. $\mathrm{m}^{-2}: 200,100,66$ e 50. Com quatro mudas, teve-se respectivamente: 400, 200, 132 e 100 plantas. $\mathrm{m}^{-2}$.

Somente as parcelas provenientes do espaçamento de $5 \mathrm{~cm}$ (com 200 e 400 plantas. $\mathrm{m}^{-2}$ ), apresentaram maior rendimento por área, diferindo significativamente dos demais tratamentos (Tabela 3). Para a comercialização em maços é interessante este resultado.

Independente da densidade de duas ou quatro mudas, não foi observada diferença significativa no rendimento por área, dentro de cada espaçamento utilizado. Embora com maior quantidade de plantas na maior densidade (400 plantas. $\mathrm{m}^{-2}$ ), o menor desenvolvimento das mesmas resultou num rendimento por área semelhante à verificada na densidade de duas mudas, com 200 plantas. $\mathrm{m}^{-2}$ (Tabela 3). Neste contexto, os resultados favoreceram a densidade de duas mudas por célula e espaçamento de 5 $\mathrm{cm}$ para obtenção de alto rendimento em massa fresca, equivalente a $3534,0 \mathrm{~g} \cdot \mathrm{m}^{-2}$. 


\section{Estação de inverno}

No outono as mudas se apresentavam no estádio de transplante aos dezenove dias da semeadura, enquanto no inverno isso ocorreu somente aos 25 dias da semeadura. Com predominância de temperaturas baixas (Figura 2), a duração do ciclo vegetativo da planta foi diferente da observada na estação de outono, com 60 dias da semeadura à colheita e ocorrendo aumento de 11 dias no ciclo.

Padulosi \& Pignone (1996) indicam como valores térmicos ótimos para a rúcula, $22-24^{0} \mathrm{C}$ durante o dia e $16-18^{\circ} \mathrm{C}$ durante a noite. Em regiões como Ponta Grossa a ocorrência de temperaturas com médias abaixo de $15^{\circ} \mathrm{C}$ é observada em vários dias, sendo previsível o aumento do ciclo (Figura 2).

Não houve interação significativa para nenhuma das características avaliadas na colheita. Para o comprimento da parte aérea (Tabela 4) não foi observado efeito significativo dos fatores trabalhados.

No entanto, na estação de inverno ocorreu maior desenvolvimento de folhas sendo observado aumento de 1,68 e 2,27 nas densidades de duas e quatro mudas (Tabela 4). $\mathrm{Na}$ densidade de duas mudas houve maior número de folhas diferindo significativamente de quatro mudas. O espaçamento entre plantas promoveu incremento significativo do número de folhas de acordo com o seu aumento; os maiores valores foram observados nos espaçamentos de 15 e $20 \mathrm{~cm}$ com diferença significativa apenas para o espaçamento de $5 \mathrm{~cm}$.

Os valores observados da massa fresca e seca por planta confirmam a sensibilidade da planta à densidade utilizada, apresentando comportamento semelhante à estação de outono (Tabela 5). Na densidade de duas mudas obteve-se massa fresca de 21,50 g, e com quatro mudas, 14,34 g, apresentando diferença de 7,16 g a favor da primeira densidade. Esta superioridade foi decorrente da maior quantidade de folhas desenvolvidas na densidade de duas mudas $(15,26)$, comparada a de quatro mudas $(11,99)$.
Houve aumento da massa fresca e seca por planta de acordo com o aumento do espaçamento, de 12,54 g no espaçamento de $5 \mathrm{~cm}$ até $23,04 \mathrm{~g}$ no de $20 \mathrm{~cm}$, com acréscimo de 10,5 g no maior espaçamento. Estes resultados demonstram que tanto o espaçamento quanto a densidade são fatores de produção que definem o tipo de produto que se objetiva produzir.

Se a comercialização fosse feita por unidade certamente espaçamentos mais amplos de 15 e $20 \mathrm{~cm}$ e densidades de duas mudas seriam os preferíveis porque promovem desenvolvimento de plantas vistosas, com mais de $22,0 \mathrm{~cm}$ de tamanho, 14,0 folhas e mais de 20,0 g de massa média.

Outro fato que deve ser considerado no comércio por unidade é a uniformidade do produto. Esta é favorecida nas condições de menores densidades e espaçamentos mais amplos, quando não é exercida a pressão de competição. Em densidades maiores, a irregularidade no desenvolvimento é mais fácil de ocorrer pois devido à competição, algumas plantas desenvolvem mais em detrimento de outras.

Reghin et al. (2004) observaram que com o aumento da densidade de mudas por célula (de uma para quatro), na característica individual da planta, houve diminuição no comprimento da parte aérea, número de folhas, peso da massa fresca e seca produzida por planta, em resposta à pressão de competição promovida pelo aumento da densidade.

No entanto, como o comércio predominante da rúcula é em maços, o rendimento promovido pelo menor espaçamento e maior densidade (400 plantas. $\mathrm{m}^{-2}$ ), transformam estas combinações mais interessantes do ponto de vista de produção. O rendimento de 3380,0 g. $\mathrm{m}^{-2}$ de massa fresca no espaçamento de $5 \mathrm{~cm}$ não foi superado por nenhum outro (Tabela 6). Observar que a mudança de $5 \mathrm{~cm}$ para $10 \mathrm{~cm}$ promoveu diminuição de $1114,8 \mathrm{~g} \cdot \mathrm{m}^{-2}$ na massa fresca, o que é significativo e representativo para o rendimento de maços. Os demais espaçamentos entre plantas $(10,15$ e $20 \mathrm{~cm})$ não apresentaram diferença significativa entre si.

TABELA 3 - Rendimento em massa fresca $\left(\mathrm{g} \cdot \mathrm{m}^{-2}\right)$ em função do espaçamento entre plantas e densidade de duas e quatro mudas por cova no cultivo da rúcula. Ponta Grossa, PR. 2003. Estação de outono.

\begin{tabular}{cccc}
\hline $\begin{array}{c}\text { Espaçamento } \\
\text { entre plantas }(\mathbf{c m})\end{array}$ & $\begin{array}{c}\text { Duas } \\
\text { Mudas por cova }\end{array}$ & $\begin{array}{c}\text { Quatro } \\
\text { Mudas por cova }\end{array}$ & Média \\
\hline 5 & 3534,0 & 4224,0 & $3879,0 \mathrm{a}$ \\
10 & 2280,0 & 2750,0 & $2515,0 \mathrm{~b}$ \\
15 & 2105,4 & 2061,8 & $2083,6 \mathrm{bc}$ \\
20 & 1818,0 & 1837,0 & $1827,5 \mathrm{c}$ \\
\hline Média & $2434,4 \mathrm{~A}$ & $2718,2 \mathrm{~A}$ & \\
\hline
\end{tabular}

*Médias seguidas da mesma letra maiúscula na linha e minúscula na coluna, não diferem significativamente entre si, no nível de 5\% de probabilidade, pelo teste de Tukey. 


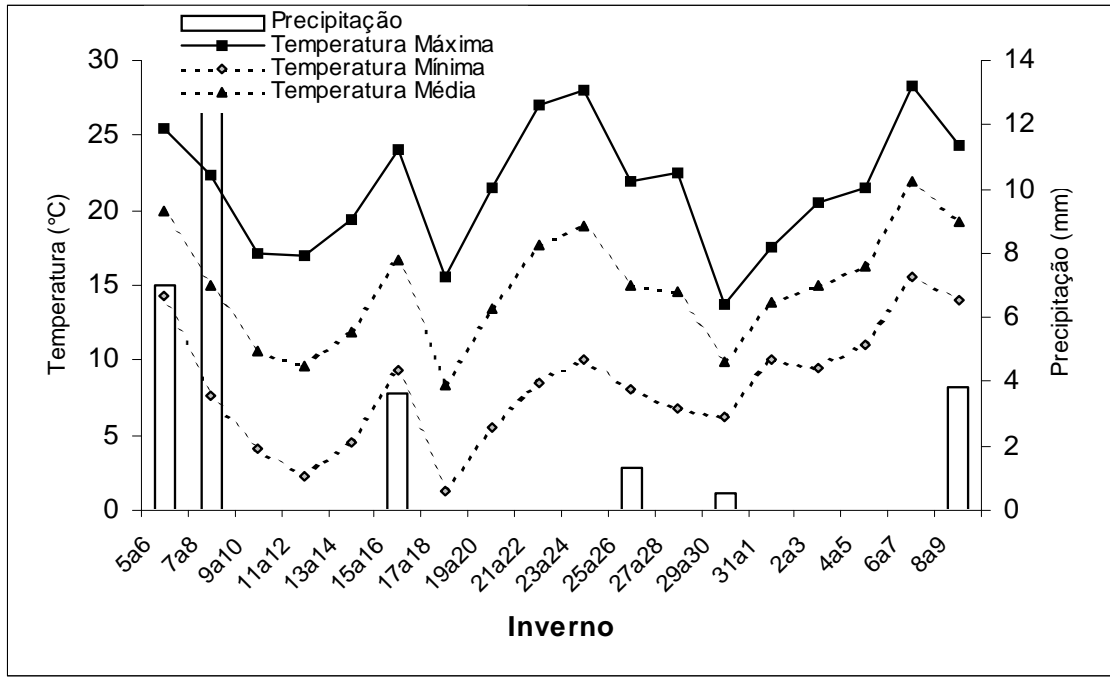

FIGURA 2 - Temperaturas máximas, médias e mínimas $\left({ }^{\circ} \mathrm{C}\right)$ a cada dois dias e soma semanal da precipitação $(\mathrm{mm})$ no período Agosto/2003 a Setembro/2003. Ponta Grossa, PR.

Dados obtidos do Instituto Agronômico do Paraná.

TABELA 4 - Comprimento da parte aérea $(\mathrm{cm})$ e número de folhas por planta, em função do espaçamento entre plantas e densidade de duas e quatro mudas por cova no cultivo da rúcula. Ponta Grossa, PR. 2003. Estação de inverno.

\begin{tabular}{ccccccc}
\hline & \multicolumn{2}{c}{ Comprimento da parte aérea $(\mathbf{c m})$} & \multicolumn{2}{c}{ Número de folhas por planta } \\
\hline $\begin{array}{c}\text { Esp. entre } \\
\text { plantas }(\mathrm{cm})\end{array}$ & $\begin{array}{c}\text { Duas } \\
\text { Mudas/cova }\end{array}$ & $\begin{array}{c}\text { Quatro } \\
\text { Mudas/cova }\end{array}$ & Média & $\begin{array}{c}\text { Duas } \\
\text { Mudas/cova }\end{array}$ & $\begin{array}{c}\text { Quatro } \\
\text { Mudas/cova }\end{array}$ & Média \\
\hline 5 & 24,93 & 22,09 & $23,51 \mathrm{a}$ & 12,10 & 9,28 & $10,69 \mathrm{~b}$ \\
10 & 21,69 & 22,10 & $21,89 \mathrm{a}$ & 15,28 & 11,64 & $13,46 \mathrm{ab}$ \\
15 & 23,44 & 22,30 & $22,86 \mathrm{a}$ & 16,03 & 12,88 & $14,45 \mathrm{a}$ \\
20 & 23,08 & 22,40 & $22,74 \mathrm{a}$ & 17,63 & 14,16 & $15,89 \mathrm{a}$ \\
\hline Média & $23,28 \mathrm{~A}$ & $22,22 \mathrm{~B}$ & & $15,26 \mathrm{~A}$ & $11,99 \mathrm{~B}$ & \\
\hline
\end{tabular}

*Médias seguidas da mesma letra maiúscula na linha e minúscula na coluna, não diferem significativamente entre si, no nível de 5\% de probabilidade, pelo teste de Tukey.

TABELA 5 - Massa fresca e seca (g/planta), em função do espaçamento entre plantas e densidade de duas e quatro mudas por cova no cultivo da rúcula. Ponta Grossa (PR). 2003. Estação de inverno.

\begin{tabular}{ccccccc}
\hline & \multicolumn{3}{c}{ Massa fresca (g/planta) } & \multicolumn{3}{c}{ Massa seca (g/planta) } \\
\hline $\begin{array}{c}\text { Esp.entre } \\
\text { plantas }(\mathrm{cm})\end{array}$ & $\begin{array}{c}\text { Duas } \\
\text { Mudas/cova }\end{array}$ & $\begin{array}{c}\text { Quatro } \\
\text { Mudas/cova }\end{array}$ & Média & $\begin{array}{c}\text { Duas } \\
\text { Mudas/cova }\end{array}$ & $\begin{array}{c}\text { Quatro } \\
\text { Mudas/cova }\end{array}$ & Média \\
\hline 5 & 16,38 & 8,71 & $12,54 \mathrm{c}$ & 1,30 & 0,73 & $1,01 \mathrm{c}$ \\
10 & 18,90 & 13,25 & $16,07 \mathrm{bc}$ & 1,62 & 0,92 & $1,27 \mathrm{bc}$ \\
15 & 23,09 & 16,98 & $20,03 \mathrm{ab}$ & 1,94 & 1,26 & $1,60 \mathrm{ab}$ \\
20 & 27,66 & 18,42 & $23,04 \mathrm{a}$ & 2,37 & 1,45 & $1,91 \mathrm{a}$ \\
\hline Média & $21,50 \mathrm{~A}$ & $14,34 \mathrm{~B}$ & & $1,81 \mathrm{~A}$ & $1,09 \mathrm{~B}$ & \\
\hline
\end{tabular}

*Médias seguidas da mesma letra maiúscula na linha e minúscula na coluna, não diferem significativamente entre si, no nível de 5\% de probabilidade, pelo teste de Tukey.

Ciênc. agrotec., Lavras, v. 29, n. 5, p. 953-959, set./out., 2005 
TABELA 6 - Rendimento em massa fresca $\left(\mathrm{g} \cdot \mathrm{m}^{-2}\right)$ em função do espaçamento entre plantas e densidade de duas e quatro mudas por cova no cultivo da rúcula. Ponta Grossa (PR). 2003. Estação de inverno.

\begin{tabular}{cccc}
\hline $\begin{array}{c}\text { Espaçamento } \\
\text { entre plantas }(\mathbf{c m})\end{array}$ & $\begin{array}{c}\text { Duas } \\
\text { Mudas por cova }\end{array}$ & $\begin{array}{c}\text { Quatro } \\
\text { Mudas por cova }\end{array}$ & Média \\
\hline 5 & 3276,0 & 3484,0 & $3380,0 \mathrm{a}$ \\
10 & 1880,5 & 2650,0 & $2265,2 \mathrm{~b}$ \\
15 & 1523,9 & 2241,4 & $1882,6 \mathrm{~b}$ \\
20 & 1383,0 & 1842,0 & $1603,5 \mathrm{~b}$ \\
\hline Média & $2015,8 \mathrm{~B}$ & $2554,4 \mathrm{~A}$ &
\end{tabular}

*Médias seguidas da mesma letra maiúscula na linha e minúscula na coluna, não diferem significativamente entre si, no nível de $5 \%$ de probabilidade, pelo teste de Tukey.

Quanto às densidades, quatro mudas foram superiores à duas mudas. $\mathrm{O}$ que corrobora com os resultados de Reghin et al. (2004), de que a densidade de quatro mudas por célula apresentou-se como recomendação viável para o cultivo da rúcula, com aumento no rendimento da massa fresca por área.

\section{CONCLUSÕES}

a) Se considerar a característica individual da planta, houve superioridade da massa fresca por planta na densidade de duas mudas e espaçamentos mais amplos, de 15 e $20 \mathrm{~cm}$;

b) Se considerar que a comercialização da rúcula é efetuada em maços, as alternativas que promoveram maior rendimento em massa fresca. $\mathrm{m}^{-2}$ foram o menor espaçamento no outono e tanto o menor espaçamento quanto a densidade de quatro mudas no inverno.

c) Houve maior precocidade de colheita na estação de outono, quando predominaram temperaturas médias em torno de $20^{\circ} \mathrm{C}$, mais favoráveis ao desenvolvimento. No inverno, com predominância de temperaturas abaixo de $15^{\circ} \mathrm{C}$, observou-se 11 dias de aumento no ciclo.

\section{REFERÊNCIAS BIBLIOGRÁFICAS}

CAMARGO FILHO, W. P.; MAZZEI, A. R. Mercado de verduras: planejamento, estratégia e comercialização. Informações Econômicas, São Paulo, v. 31, n. 3, p. 45-54, 2001.

FILGUEIRA, F. A. R. Novo manual de olericultura: agrotecnologia moderna na produção e comercialização de hortaliças. Viçosa: UFV, 2000. 402 p.

MINAMI, K.; TESSARIOLI NETO, J. A cultura da rúcula. Piracicaba: ESALQ, 1998. 19 p.

PADULOSI, S.; PIGNONE, D. Rocket: a Mediterranean crop for the world. Rome: International Plant Genetic Resourses Institute, 1997. $101 \mathrm{p}$.

REGHIN, M. Y.; OTTO, R. F.; VINNE, J. van der. Efeito da densidade de mudas por célula e do volume da célula na produção de mudas e cultivo da rúcula. Ciência e Agroctecnologia, Lavras, v. 28, n. 2, p. 287-295, 2004.

TAKAOKA, M.; MINAMI, K. Efeito do espaçamento entre-linhas sobre a produção de rúcula (Eruca sativa). O Solo, Piracicaba, v. 76, n. 2, p. 51-55, 1984. 